\title{
The Past and Future of Co-Creation: An Abstract
}

\author{
Alexander J. Kull
}

\begin{abstract}
This research critically examines the current understanding of co-creation in light of its preceding and associated concepts. Tracing co-creation back to its origins and precursors within and beyond the marketing literature helps position co-creation and capture its complexity and potential. Drawing on this review and stakeholder theory, the paper develops propositions that expand co-creation beyond its current scope. These propositions offer (1) an extended definition of co-creation including all stakeholders, (2) a broadened understanding of value directly and indirectly co-created by stakeholders, and (3) a triadic framework in which the company, contractual stakeholders, and community stakeholders co-create value in an overarching social system. The paper concludes with implications and directions for further research.
\end{abstract}

References Available Upon Request

\author{
A.J. Kull ( $\square)$ \\ University of San Diego, San Diego, CA, USA \\ e-mail: akull@sandiego.edu
}

